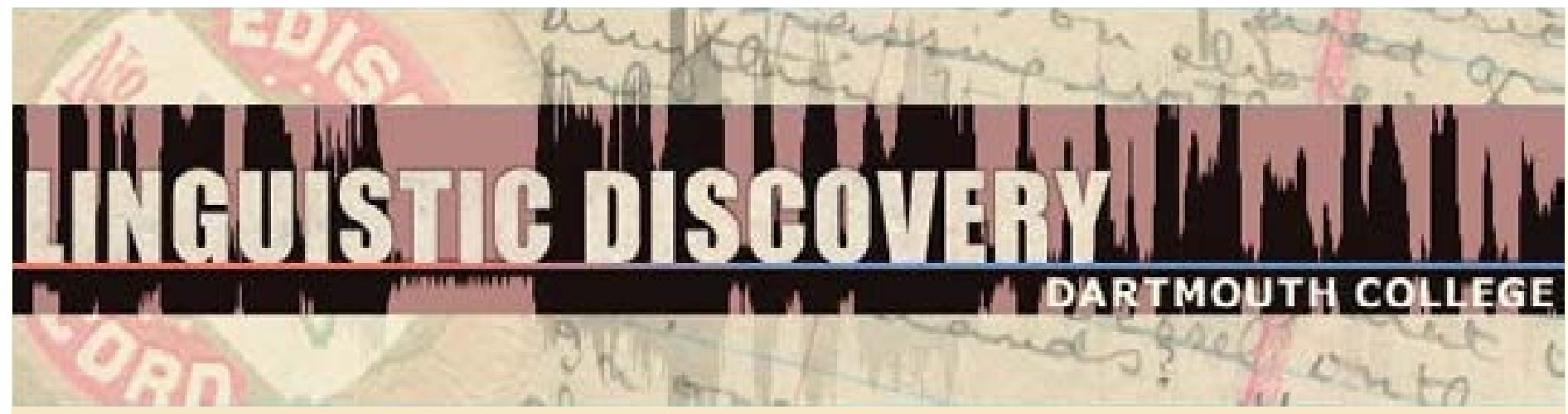

Volume 4 Issue 1 2006

\section{The Iquito Language Documentation Project: Developing Team-Based Methods for Language Documentation}

Christine Beier and Lev Michael

University of Texas at Austin

doi: 10.1349/PS1.1537-0852.A.303

url: http://journals.dartmouth.edu/cgi-bin/WebObjects/ Journals.woa/1/xmlpage/1/article/303 


\title{
The Iquito Language Documentation Project: \\ Developing Team-Based Methods for Language Documentation
}

\author{
Christine Beier and Lev Michael \\ University of Texas at Austin
}

\section{What is the ILDP?}

The Iquito Language Documentation Project (ILDP) is a team-based, community-participatory, multi-year project that supports Iquito community language revitalization efforts.

\section{The Iquito language. . .}

- is highly endangered. Iquito - pronounced [i.'ki.tu] - presently has about 25 fluent native speakers, all over 55 years of age; and has about 25 passive or partial speakers, all over 30 years of age.

- is one of three surviving Zaparoan languages, along with Záparo (1 to 3 speakers) and Arabela (75 speakers). The other four, Andoa, Aushiri, Cahuarano, and Omurano, are now extinct.

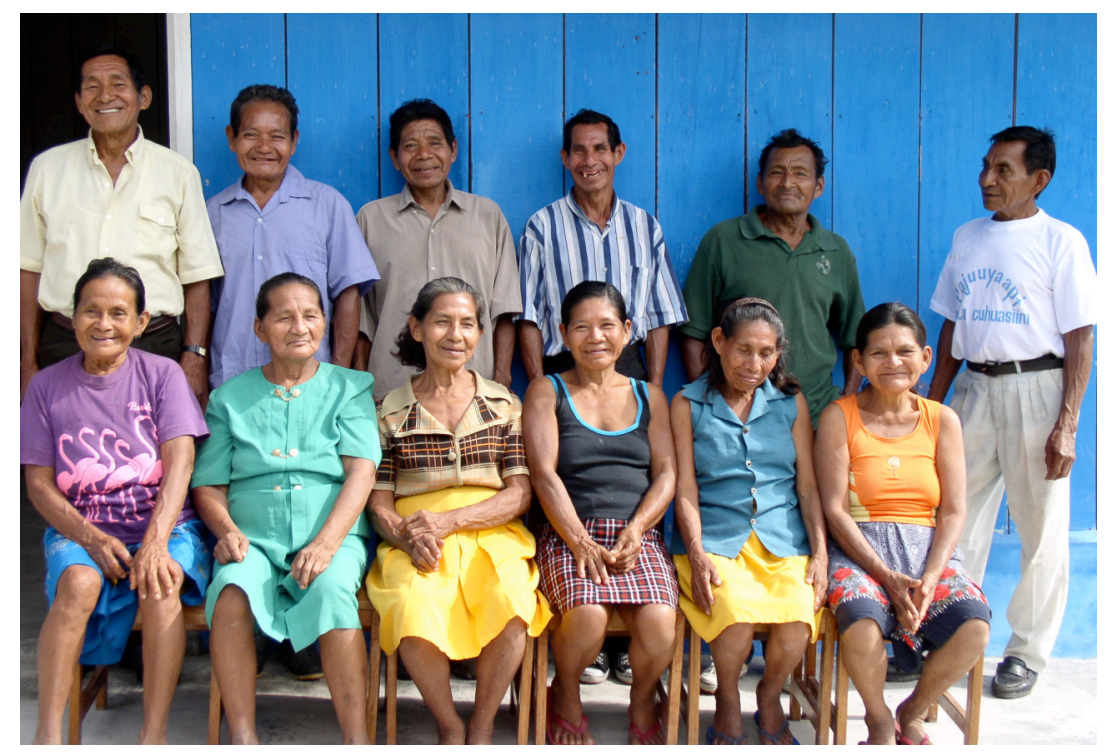

Twelve of the remaining 25 speakers of lquito, at a lunch in their honor (July 2004)

The ILDP. . .

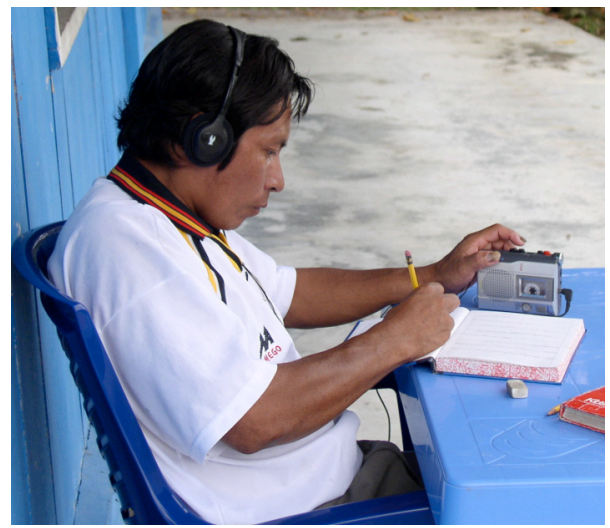

Community linguist Marcelo Inuma transcribes a text (August 2004)
- is funded, from 2003 to 2006, by the Endangered Languages Documentation Programme of the Hans Rausing Endangered Languages Project, under Major Documentation Grant \# MDP0042. The ILDP was also funded by the Endangered Language Fund between 2002 and 2003.

- at its conclusion will have produced a descriptive grammar, an Iquito-Spanish dictionary, a collection of audio, video and written texts, and pedagogical materials for community use. 


\section{Where is the ILDP?}

- The Iquito language is spoken principally in and near the indigenous communities of San Antonio, on the Pintuyacu River, and Atalaya, on the Chambira River, in the departamento of Loreto, Perú.

- The ILDP is based in San Antonio, 100 kilometers due west of the city of Iquitos. San Antonio is a community of about 180 people, most of whom are subsistence farmers.

\section{Who is the ILDP?}

- The ILDP's PI is Dr. Nora England, Director of The Center for Indigenous Languages of Latin America at The University of Texas at Austin.

- Co-PIs are Christine Beier and Lev Michael, doctoral candidates in linguistic

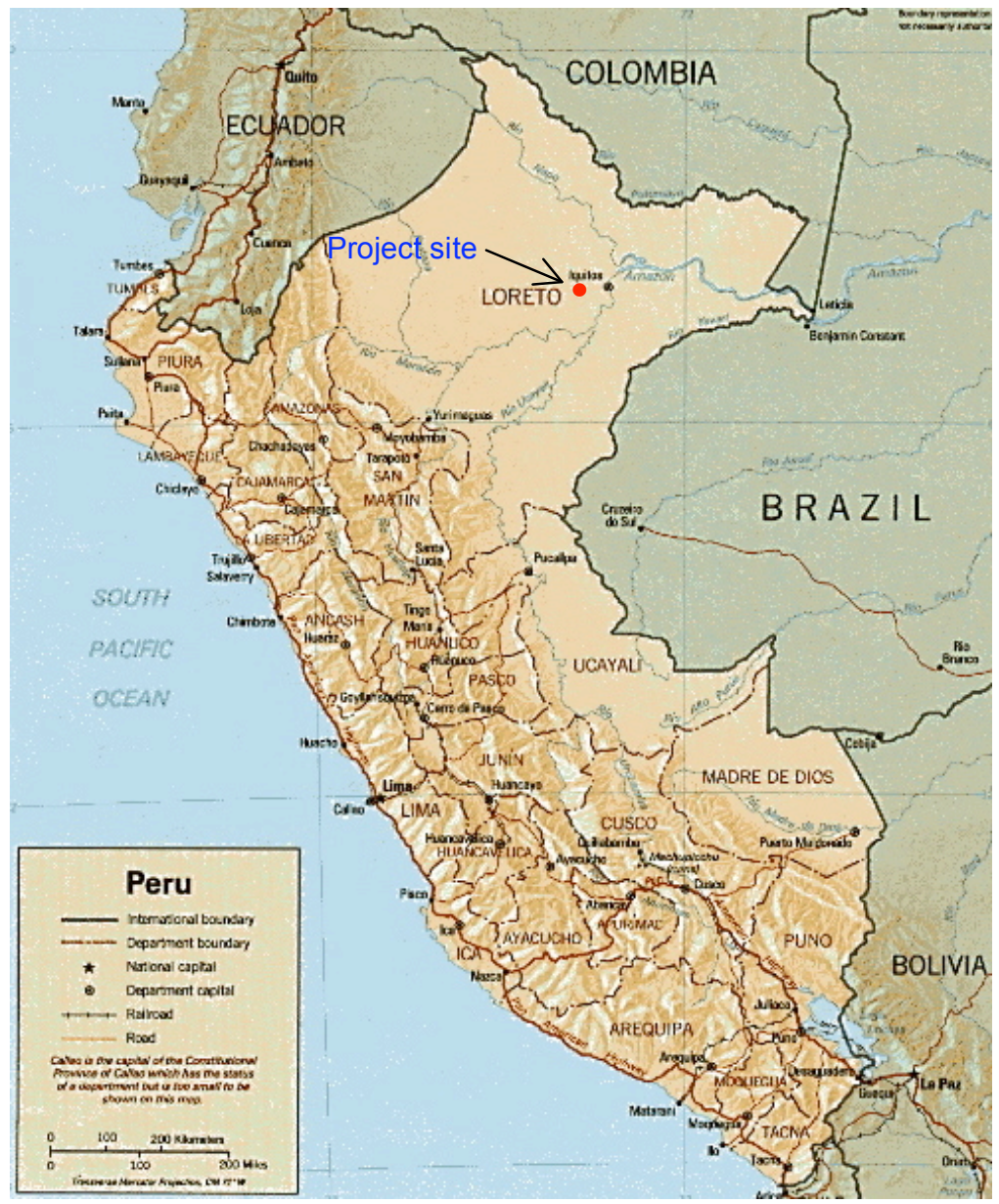
anthropology at UT-Austin and co-founders of the NGO Cabeceras Aid Project.

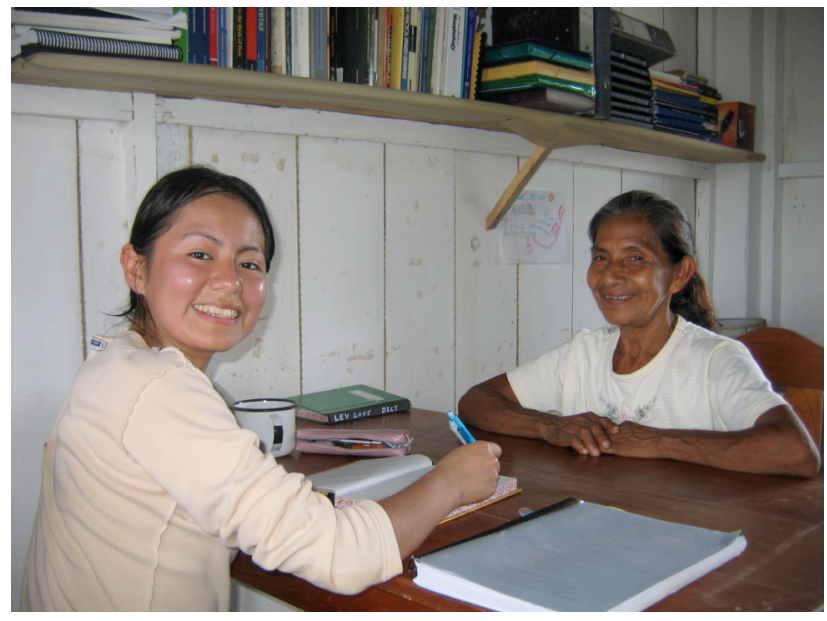

Sisi Bautista consults with Ema Llona on a text transcription (June 2005)
- Other research team members for the ILDP include graduate students in linguistics from UT-Austin and from the Universidad Nacional Mayor de San Marcos in Lima, Perú. The following graduate students have participated in the ILDP: Cynthia Anderson (UT-Austin, 2004 and 2006); Sisi Bautista Pizarro (U de San Marcos, 2005); Mark Brown (UTAustin, 2002 and 2003); Taryne Hallett (UT-Austin, 2004); Molly Harnisch (UTAustin, 2005); Edinson Huamancayo Curi (U de San Marcos, 2003 and 2004); Lynda de Jong (UT-Austin, 2002 and 2003); Iwen Lai (UT-Austin, 2003, 2005, and 


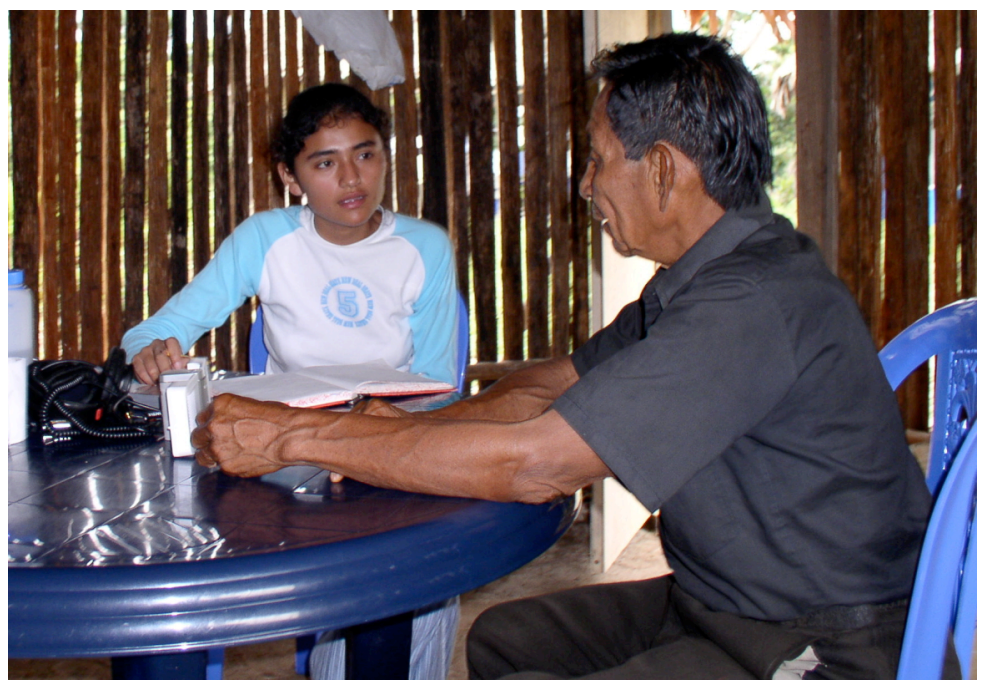

Karina Sullón working on phonology with lquito consultant Jaime Pacaya (July 2004)
2006); Brianna Rauschuber (UTAustin, 2005 and 2006); Karina Sullón Acosta (U de San Marcos, 2004 and 2005).

- Community team members include four native speakers of Iquito; and two community linguists who are ethnically Iquito and whose first language is Spanish. The following native speaker consultants have participated in the ILDP: Hermenegildo Díaz Cuyasa (2002 - 2006); Ligia Inuma Inuma (2003 - 2006); Ema Llona Yareja (2002 - 2006); Jaime

Pacaya Inuma (2002 - 2006); Trinidad Pacaya Inuma (2002 - 2003). The following community linguists have participated: Miroslava Güimack Llona (2002 - 2003); Marcelo Inuma Sinchija (2003 - 2006); Hilter Panduro Güimack (2002 - 2006); Arturo Vargas Tuisima (2002 - 2003).

\section{ILDP Timeline}

- In July of 2001, Beier and Michael first visited San Antonio as representatives of the NGO Cabeceras Aid Project. An agreement to collaborate in a multi-year revitalization project was established between Cabeceras and the community of San Antonio.

- In May 2002, the Iquito Language Center was built in San Antonio, funded by Cabeceras; and the Endangered Language Fund awarded Cabeceras one year of salaries for the community team.

- In June 2002, the first team of researchers visited San Antonio. Beier and Michael provided intensive training in basic descriptive linguistics to community linguists. Community team members began to work year-round on language documentation.

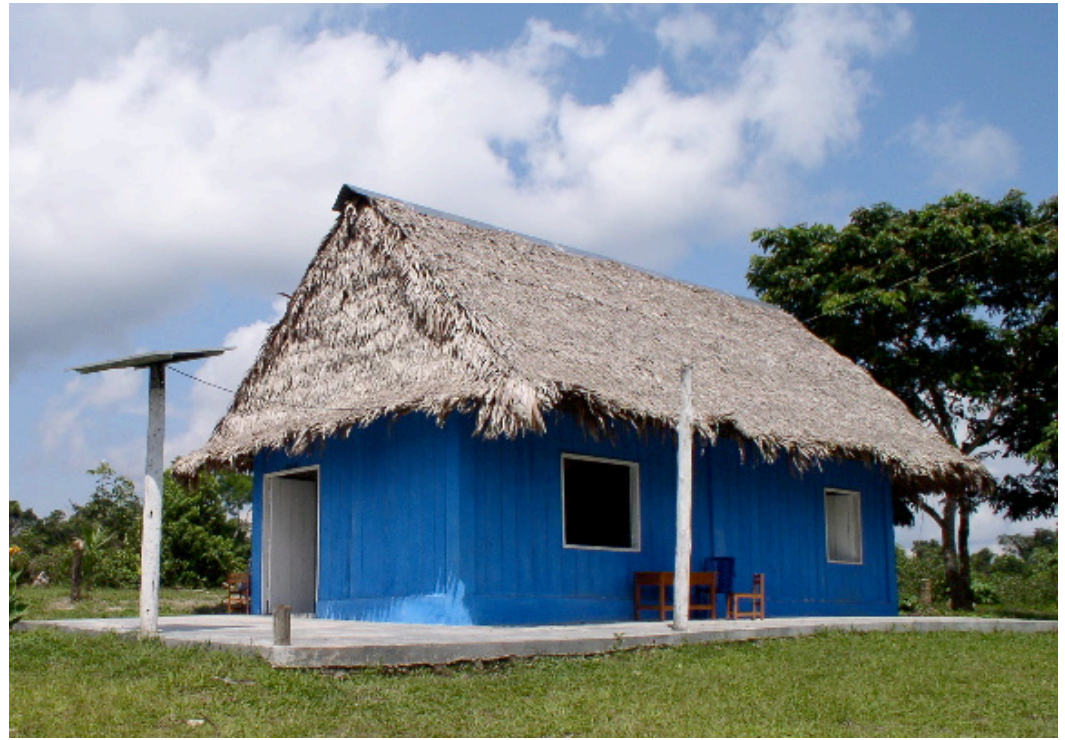

The Iquito Language Center - note solar panels at left (July 2003) 


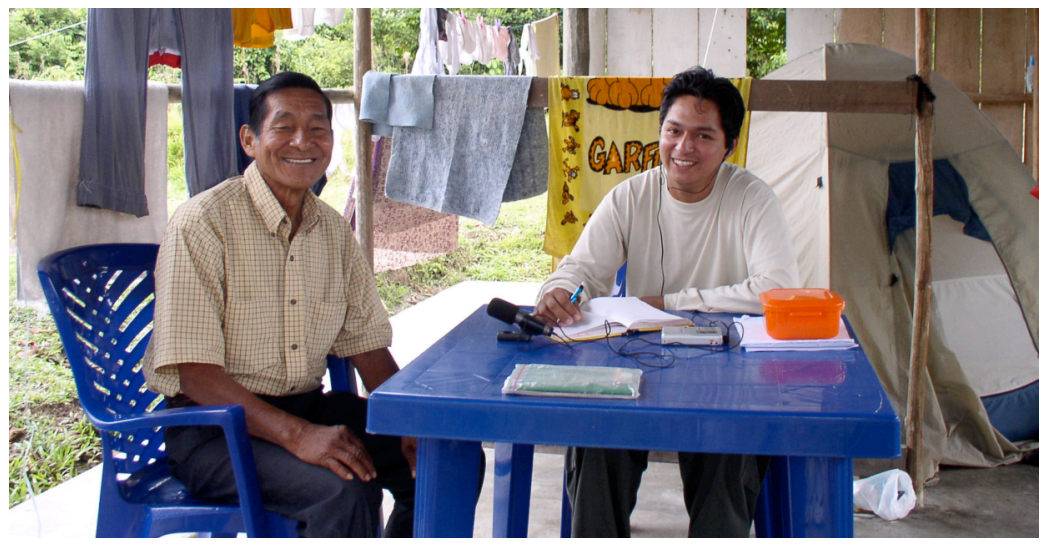

Iquito consultant Hermengildo Díaz and team member Edinson Huamancayo work together during an elicitation session (July 2004)
- In March 2003, the ELDP awarded Grant \# MDP0042 to the ILDP through UT-Austin. The grant funds equipment; community salaries; and visiting researchers' costs and stipends.

- From June to August of 2003, 2004, and 2005, teams of graduate students have collaborated with community members in San Antonio on

documentation and revitalization of Iquito.

- From May to December 2006, the research team will generate the project's final products.

\section{What are the goals of the ILDP?}

\section{Intensive Documentation}

- To produce multi-media documentation of Iquito. Textual, audio, and video materials with diverse content facilitate thorough and accurate linguistic description of Iquito.

- To provide these materials to the heritage language community, to use as they see fit.

- To provide information in and on Iquito to a wide audience of interested parties, including other indigenous groups and federations, linguists, anthropologists, and historians.

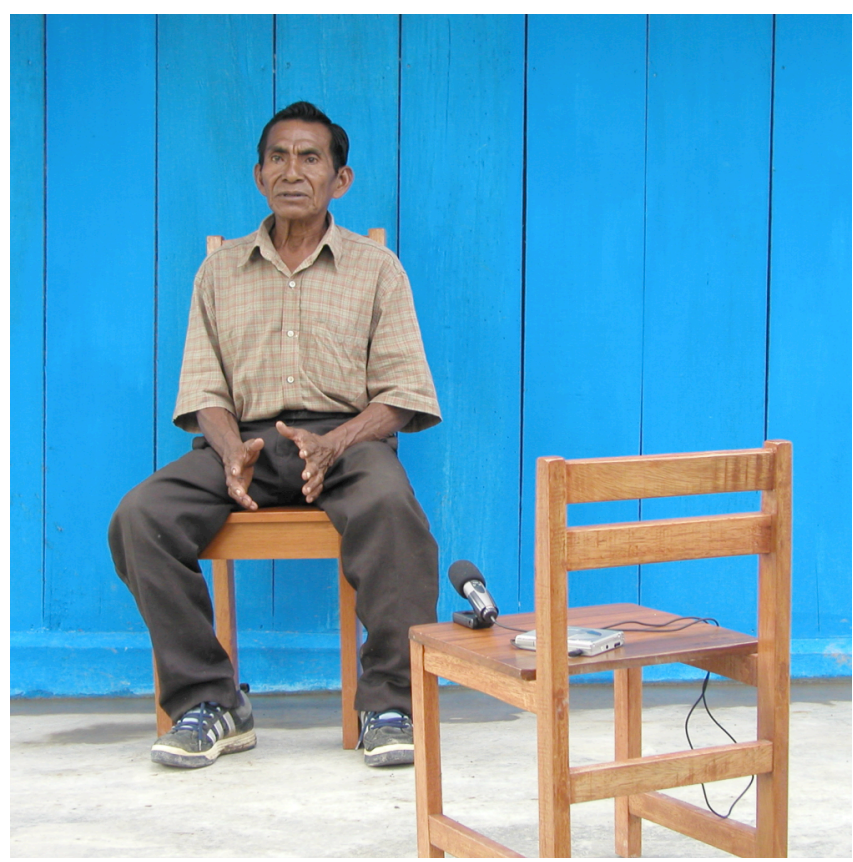

Jaime Pacaya relates a historical narrative of the migration of the lquito people from the headwaters of the río Pintuyacu to the río Amazonas (July 2002).

\section{Innovative Methods}

- To develop a methodology for relatively rapid documentation of a language in which:

$\rightarrow$ graduate students can contribute significantly to language documentation and description during medium-length field stays, without needing to participate during the entire length of the project.

$\rightarrow$ community members can actively participate in the creation of language documentation and in decisions regarding the representation and teaching of their heritage language. 


\section{Disciplinary Contribution}

- To increase the number of linguists working on Amazonian languages by providing research opportunities to US and Peruvian graduate students at early stages in their careers.

\section{Methodological priorities of the ILDP}

\section{Work in collaborative research teams}

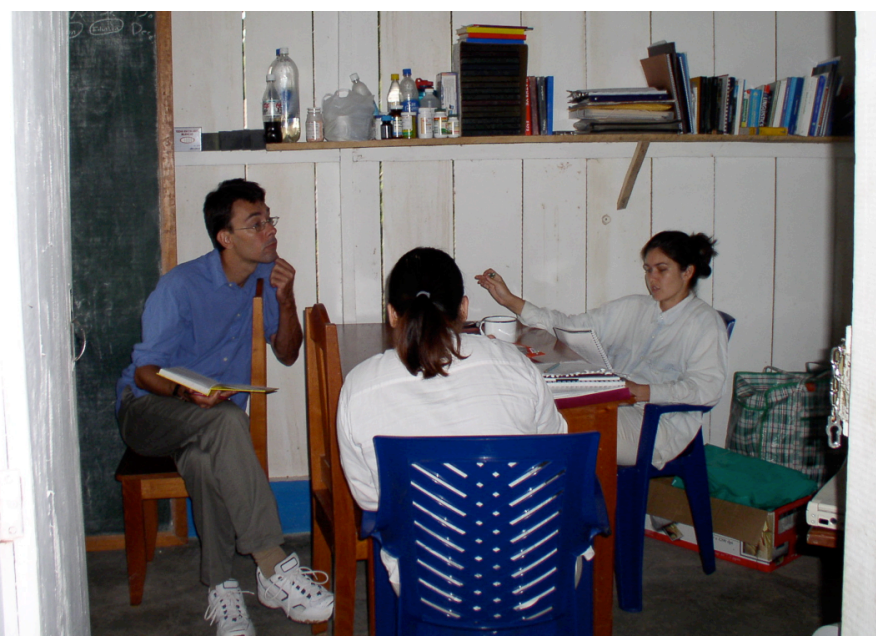

Team members Lev Michael, Iwen Lai, and Lynda De Jong ( $L$ to $R$ ) discuss an analysis of Iquito grammar (June 2003)
- Diversity: Team members' different specializations improve the quality of documentation.

- Collaboration: Teamwork establishes a local community of scholars whose collaborative efforts greatly improve the quality of linguistic description and analysis produced.

- Productivity: Teamwork generates a large number of person hours per field season.

\section{Emphasize fieldwork}

- Uninterrupted two-month field stays insure researchers' immersion in the heritage language community; continuous access to consultants; continuous access to other researchers; few distractions; shared work ethic of high productivity.

3. Produce documentary and descriptive materials continuously over the life of the project

- Producing materials continuously makes data and analyses promptly available to members of the team, as they tackle related and more

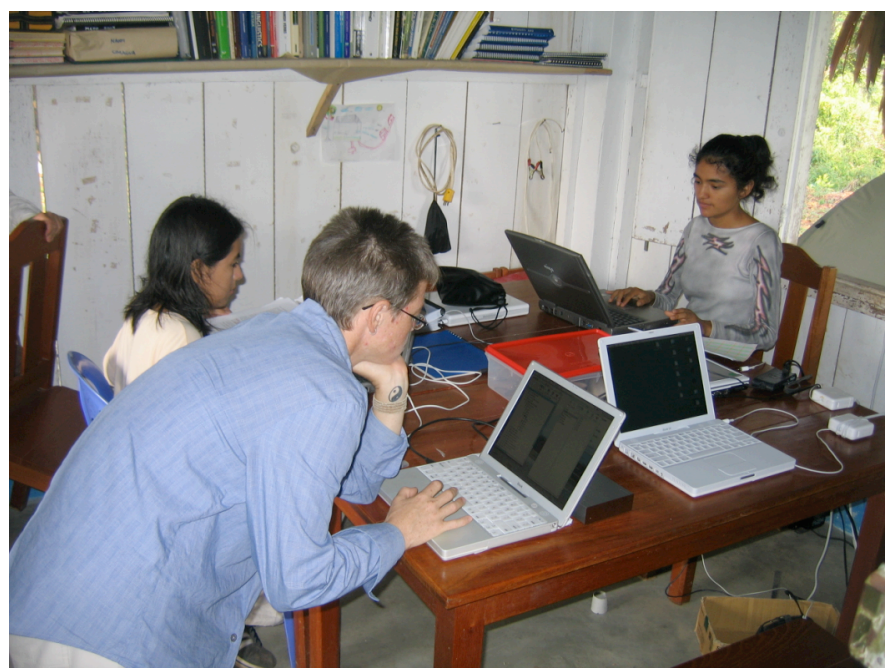

Sisi Bautista, Christine Beier, and Karina Sullón ( $L$ to $R$ ) at work on texts, grammatical description, and the dictionary, respectively (August 2005). advanced topics.

- Generating specific products in fixed timeframes organizes research activities and planning. 
- Continuously producing materials paces the project, avoiding a 'logjam' at the end.

\section{Foreground community concerns and involvement in language revitalization}

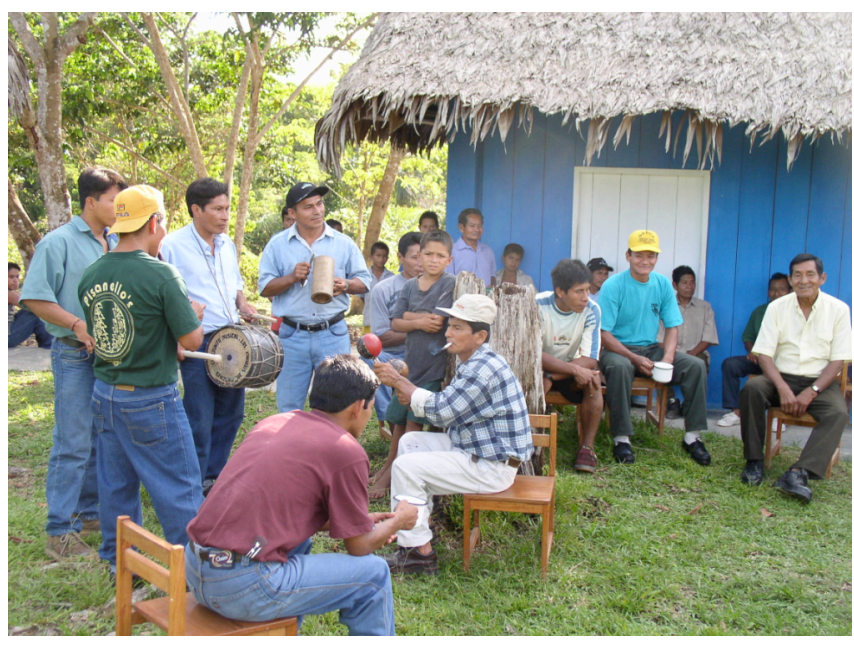

A community band plays at a fiesta in honor of lquito speakers (July 2004).

- Both community members and graduate students (from the US and Peru) are under-utilized sources of talent and productivity for language documentation activities.

- Graduate students are flexible, enthusiastic, and need field training.

- Undocumented languages in the Amazon Basin need skilled researchers. Involving graduate students in fieldwork early in their careers increases the pool of Amazonian linguists.

The ILDP uses four innovative methods to carry out team-based research:

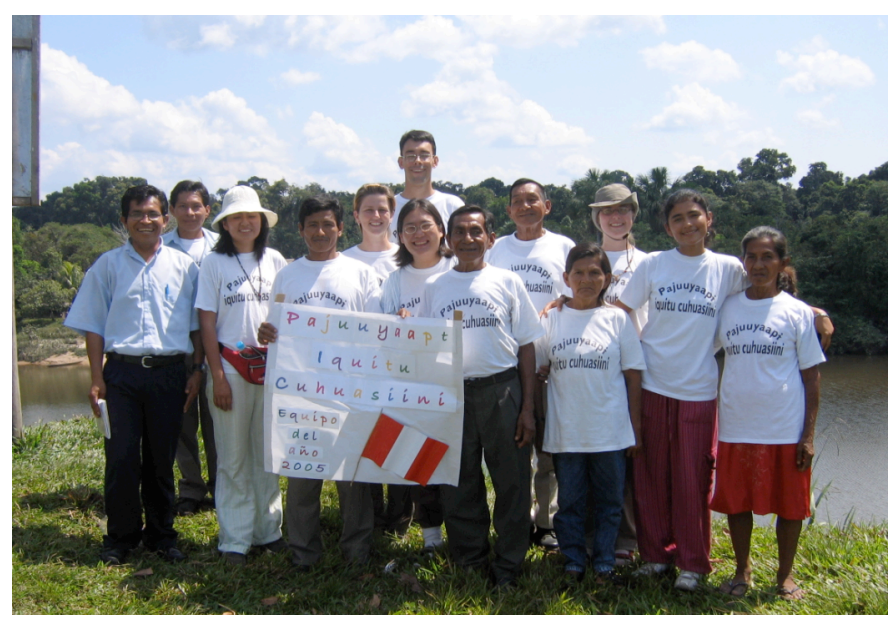

The ILDP team - consultants, community linguists, and graduate students - after having participated in the community's annual Fiestas Patrias parade (August 2005).

\section{Team-based methods developed by the ILDP}

\section{The Module-and-Seminar Model for Collaborative Linguistic Fieldwork}

\section{The Modules}

- Each week, each team member works intensively on a defined research topic. 
- The team member writes up their research on that topic as a module. The researcher presents this module during a weekly seminar, then revises it to produce a final version of the module.

- At the end of each field period, all the final modules are copied, bound, and distributed among all team members, to facilitate future research and analysis.

\section{The Seminars}

- Each week, each team member presents a new module during a two-hour team seminar, eliciting comments and discussion from the rest of the team members.

- Seminars and modules keep the entire team up-to-date on advances in specific research areas.

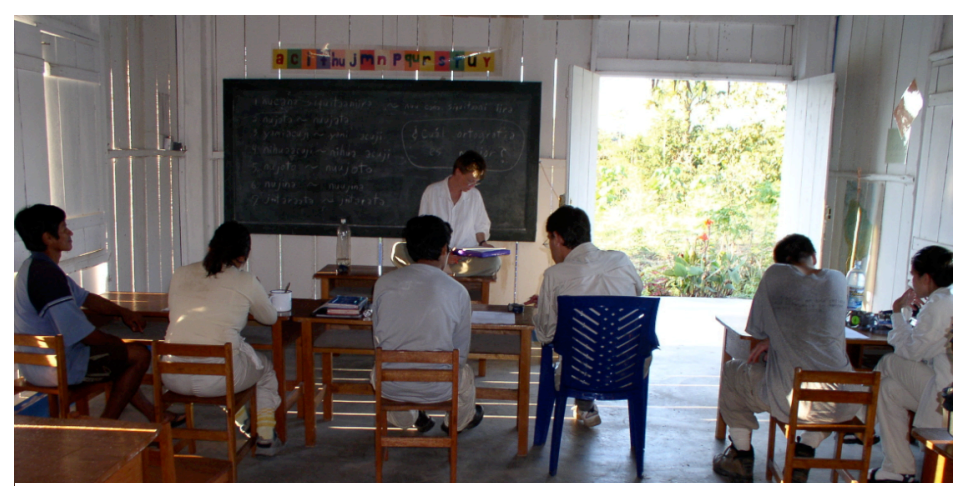

Christine Beier presents a module during the daily ILDP seminar (August 2003)

\section{The Project Coordinators}

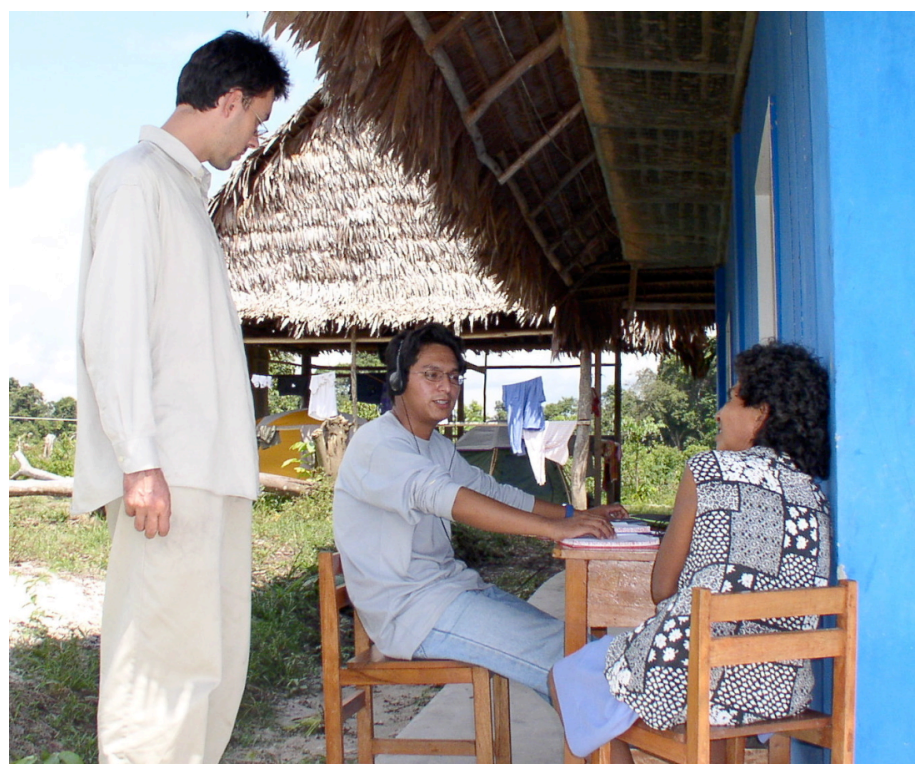

Descriptive grammar coordinator Lev Michael converses with Edinson Huamancayo and Iquito consultant Ema Llona during an elicitation session (July 2003).
- Coordinators are researchers committed to the project for its entire length.

- In consultation with all team members, they coordinate the team's research activities, module topics and work schedule for all the researchers in their respective areas.

- Coordinators consult with and guide team members in their data collection and analysis.

- The ILDP's coordinators are Christine Beier (for texts and pedagogical materials); and Lev Michael (for descriptive grammar and dictionary).

\section{Training and continuous participation of Community Linguists}

- The project coordinators provide instruction to community linguists in relevant aspects of phonology, morphology, and syntax so that they can participate in language documentation. 
- A team of four Iquito speakers and two community linguists are employed year-round, transcribing and translating texts; and gathering lexical material for the dictionary.

- Decisions about the representation of the language in texts and in the dictionary, and about the design of pedagogical materials, are made by the community linguists and specialists.

\section{Community Governance of Project}

- The ILDP holds itself accountable to the Iquito community. Project administrators report to the community assembly and respond to questions and concerns regarding project

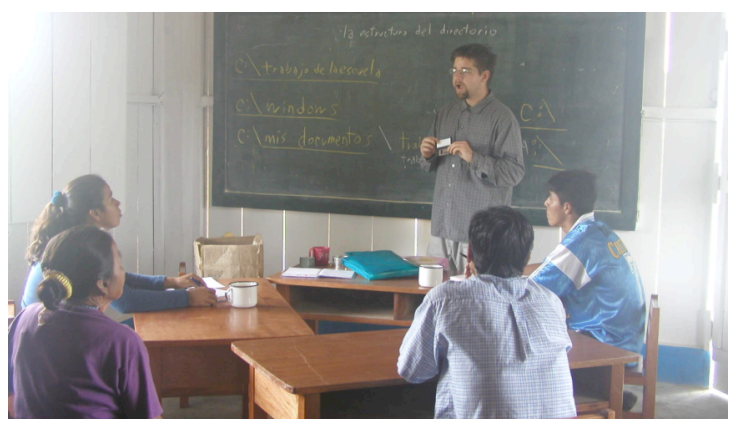

Mark Brown teaches a tutorial on computer use (July 2002) activities.

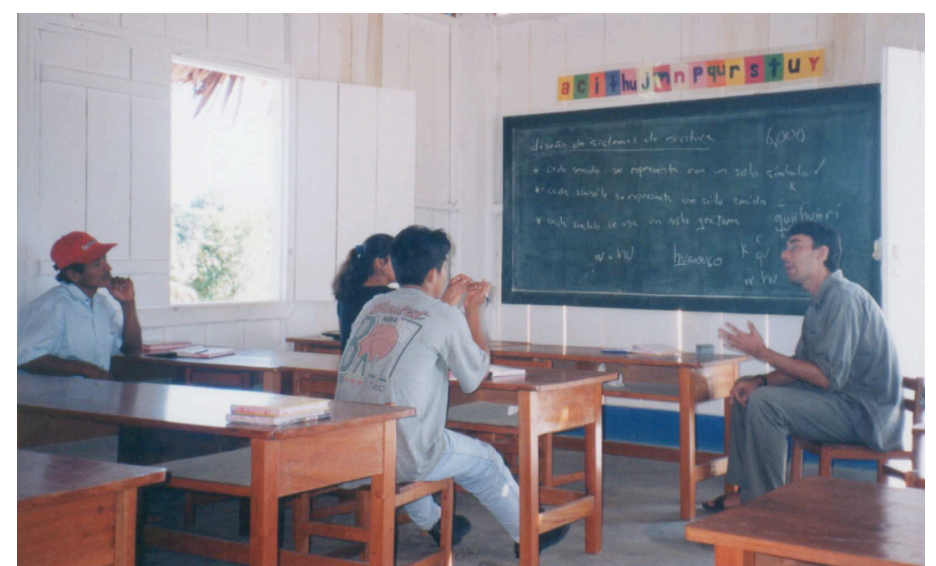

Lev Michael leads a discussion on orthography design (July 2002)

- The modules written each week provide the foundation for the final descriptive grammar of Iquito. Modules provide extensive discussion of their topics as well as numerous examples, allowing the research team to continuously build and refine analyses of the Iquito language.

- The final materials are being authored by a team of researchers based on workplans and outlines that have been evolving over the entire life of the project.
- Each year, the administrative structure of the ILDP has adapted to evolving social and political priorities of the Iquito community, in order to remain faithful to the project's core goal of producing materials valued by and useful to the Iquito heritage language community.

\section{Cumulative and collaborative preparation of the ILDP's final materials}

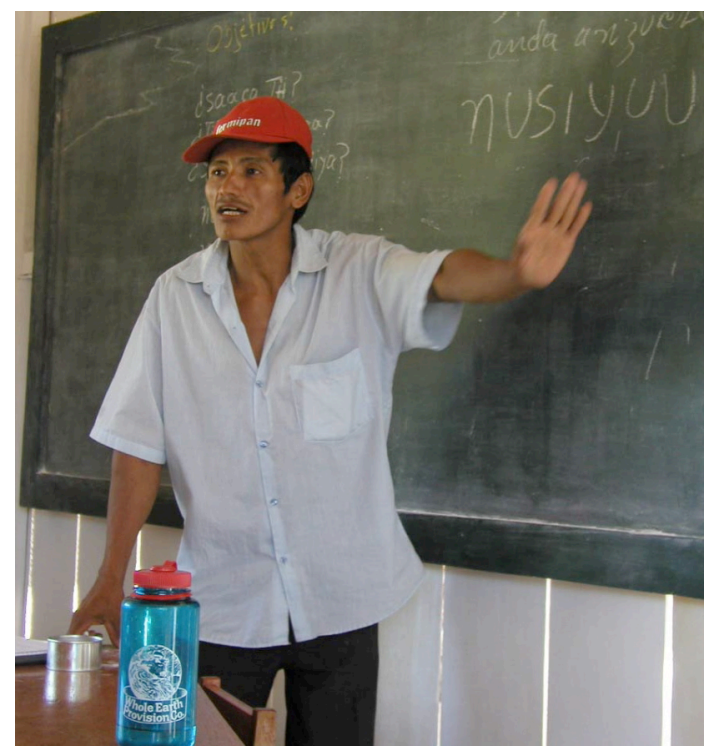

Community linguist Hilter Panduro makes a point about the Iquito orthography (July 2002) 


\section{The life-cycle of a research topic...}

Day 1: A research topic is assigned to the team member. The coordinator and team member discuss research objectives and data collection methodology. The team member begins data collection.

Days 2 to 5: Team member collects data and develops analysis, consulting with other team members and coordinators.

Days 5 to 6: Team member writes a 'module' presenting the data and analyses for the topic.

Day 6: Team member presents this module during afternoon seminar with all team members and coordinators. The whole team discusses the data and analyses. After seminar, the team member and coordinator meet to discuss changes and/or additions, based on the seminar discussion, for the final version of the module.

Day 7+: A final version of the module is prepared for inclusion in the project-internal yearly working papers. Team member is assigned new topic, and the cycle continues...

\section{Evaluation of the ILDP: Successes}

\section{Producing extensive documentation and description of the Iquito language}

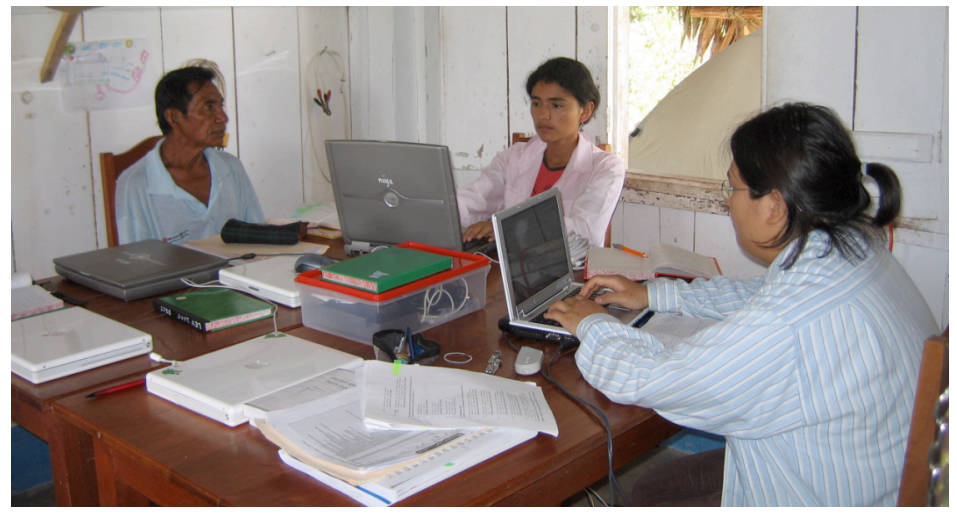

Iquito consultant Jaime Pacaya works with Karina Sullón on the dictionary while Iwen Lai prepares a module (June 2005).
- The project has thus far produced 94 modules, about 1500 pages of linguistic description, 5500 lines of transcribed and translated texts, 300 hours of audio and/or video recorded narratives, conversations, and elicitation sessions, and a variety of interactive language teaching materials.

\section{Involving students in Amazonian linguistics}

- A total of twelve students have participated in the ILDP, from both UT-Austin and U de San Marcos in Lima, few of whom would have worked on an Amazonian language otherwise. (See list above).

- Three US graduate students have written MA theses and two Peruvian students have written Licenciatura theses on aspects of Iquito. The following theses have been written:

Brown, Mark C. 2004. Topics in Iquito syntax : word order, possession, and nominal discontinuity. Master of Arts Thesis. Austin: University of Texas.

de Jong Bouldreault, Lynda. 2005. The Iquito Clause: Simple and Multi-Verb Constructions. Qualifying Paper. Austin: University of Texas.

Huamancayo Curi, Edinson Y. 2005. La Formación de Palabras Mediante la Derivación en Iquito. Tesis de Licenciado Lima: Universidad Nacional Mayor de San Marcos. 
Lai, I-wen. 2005. Fundamental Aspects of the Iquito Language. Qualifying Paper. Austin: University of Texas.

Sullón Acosta, Karina N. 2005. El acento y tono en la Lengua Iquito. Tesis de Licenciado. Lima: Universidad Nacional Mayor de San Marcos.

- Three more MA theses and another Licenciatura thesis are currently being written by the following graduate students on the following topics:

Cynthia Anderson (Adverbs in Iquito); Sisi Bautista Pizarro (Pragmatics of adjective position in Iquito): Taryne Hallett (Deontic constructions in Iquito).

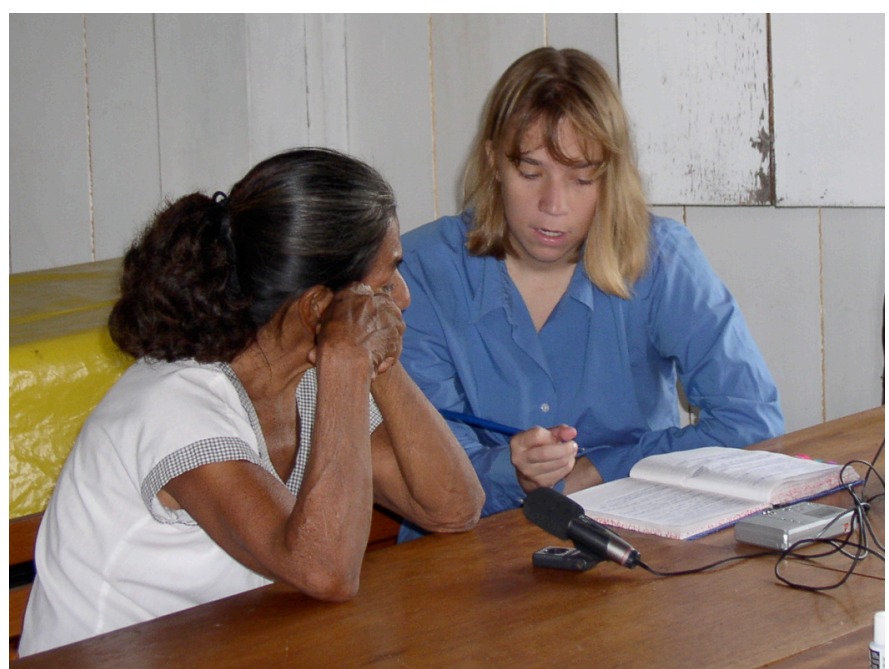

Cynthia Anderson works with Iquito consultant Ema Llona during an elicitation session (July 2004).

- In 2006, I-wen Lai will be carrying out dissertation fieldwork and writing her dissertation on aspect and verb classes in Iquito.

\section{Actively Involving Community Members in Language Documentation}

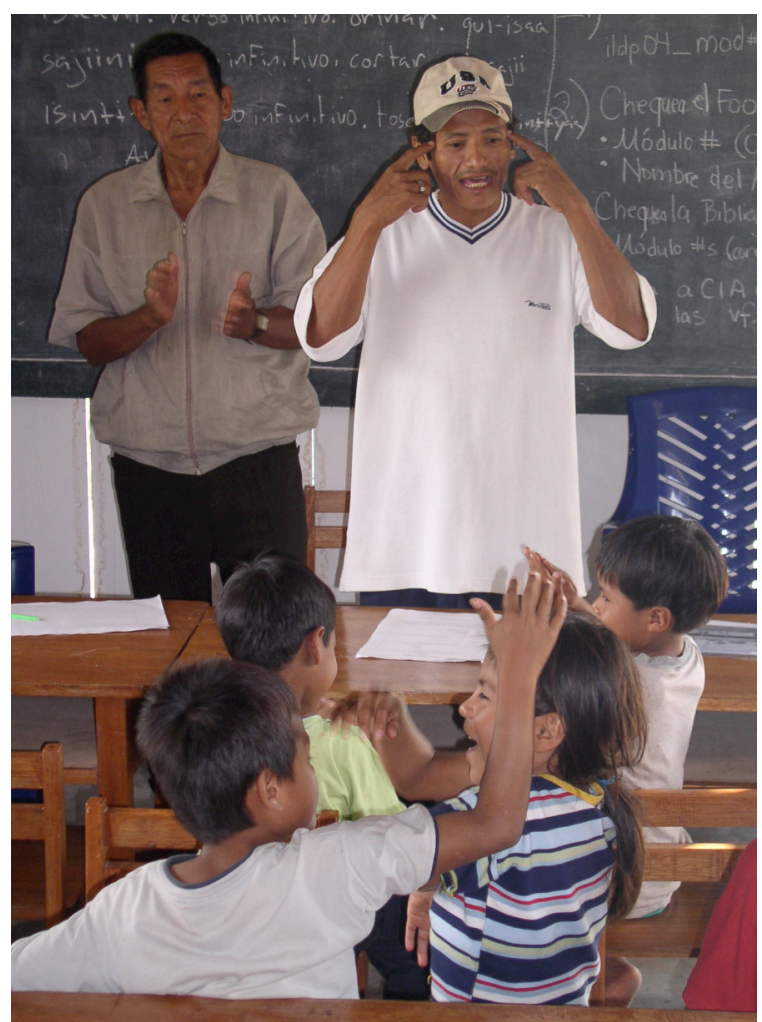

lquito speaker Hermenegildo Díaz and community linguist Hilter Panduro teach a children's lquito language class (August 2004)
- Community Linguists have risen to the challenge of making all major orthography decisions, and have also contributed significantly to the design of the IquitoSpanish dictionary and the pedagogical materials for the community's bilingual school.

- Lexical work has benefited tremendously from the participation of the community linguists, who have done the majority of data collection to this point. Their knowledge of the local environment, of local technologies, and of Iquito social practices has resulted in a very fine-grained account of many important semantic domains.

- Community Linguists and Language Specialists have taught in the community school in partnership with the official bilingual schoolteachers, significantly increasing the quantity and quality of Iquito language instruction in the community. 


\section{The Coordinator-and-Seminar Model for Collaborative Linguistic Fieldwork}

- The Model has made it possible to integrate students, who may only participate for a single twomonth field season, into a research program in which they can be very productive.

- The Model permits rapid communication of research advances among team members, ensuring that each researcher's findings inform the work of others.

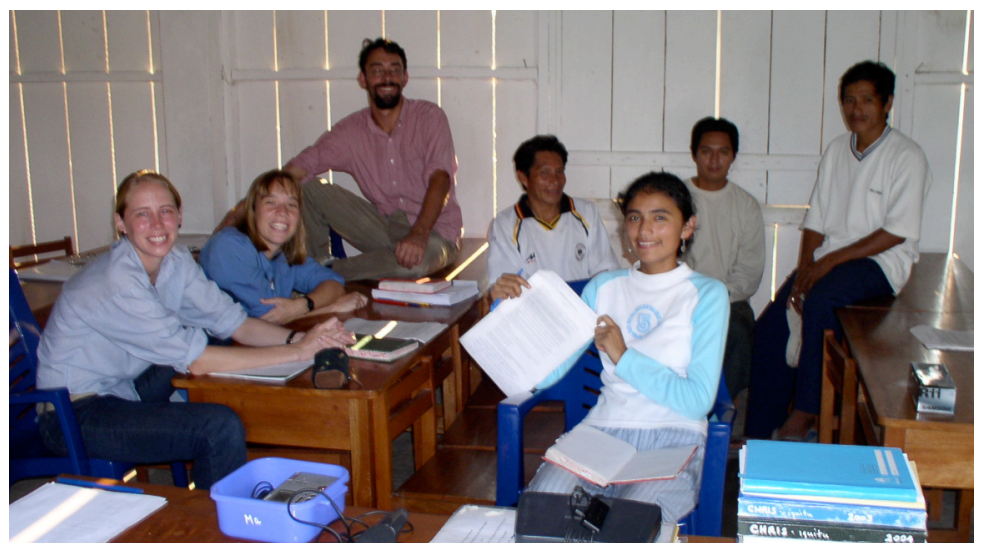

Team members celebrate the final module of the 2004 field season (August 2004).

- Weekly module deadlines compel a high level of continuous productivity during the field season.

\section{Evaluation of the ILDP: Challenges}

1. Introducing new team members in the latter years of the project

- New team members at times had to quickly master a considerable body of previous research on Iquito, in order to contribute to the advanced topics that remained to be investigated.

\section{Difficulty of achieving committee-based community governance}

- The committee-based governance system with which the project was originally designed did not fit the reality of the community's political system.

- As a result, through the decision of community members, the language specialists, and the community linguists, in 2003 one of the community linguists was chosen as a project administrator who is responsible to the community assembly. In 2004 the position rotated to the other community linguist. 